\title{
Utilization of the emergency room: impact of geographic distance
}

\author{
Jae Eun Lee ${ }^{1}$, Jung Hye Sung 2 , William B. Ward ${ }^{3}$, Peter J. Fos ${ }^{4}$, Won Jae Lee ${ }^{5}$, Jae Chang Kim ${ }^{6}$ \\ ${ }^{1}$ Methodist Rehabilitation Center, 1350 East Woodrow Wilson, Jackson, Mississippi, USA; ${ }^{2}$ Jackson State \\ University, 1400 Lynch St., Jackson, Mississippi, USA; ${ }^{3}$ USF Health, 13201 Bruce B. Downs Blvd MDC \\ 56 Tampa, Florida 33612, USA; ${ }^{4}$ The University of Southern Mississippi, 118 College Drive, Hattiesburg, \\ Mississippi, USA; ${ }^{5}$ Kynngwon University, San 65, Bokjung-dong, Sujung-gu, Sungnam-Si, Republic of \\ Korea; ${ }^{6}$ Kangwon National University, Hyoja-dong, Chuncheon-si, Kangwon-do, Republic of Korea
}

\begin{abstract}
The aim of this study was to estimate the distance Mississippi patients must travel to access hospital-based emergency rooms (ERs) and to determine whether an association exists between geographic distance and ER utilization. To that end, great circle distances between Census Block Group Centroid Points and 89 hospitals with emergency departments were calculated for the State of Mississippi. Data on the socio-demographic characteristics of each block group came from the 2000 US Census data. Logistic regression analyses were conducted to test if there was any association between ER utilization and travel distance. Compared to the national benchmark of $35.7 \%$, more than one in two $(56.7 \%)$, or 1,612,762 Mississippians visited ERs in 2003 with an estimated 6.1 miles per person annual travel for this purpose. The majority of the target population $(54.9 \%)$ was found to live within 5 miles of hospitals with ERs. Logistic analyses revealed that block groups associated with less miles traveled to hospitals with ERs had a higher proportion of African Americans, impoverished people, female householders, people with more than 12 years education, people older than 65 years, people with high median house values, and people without employment. Twenty-nine of the 89 hospitals $(33 \%)$ providing ER care in Mississippi were found to be in areas with above-average ER utilization rates. These hospitals served a smaller geographical area ( $28 \%$ of the total) but had a greater proportion of visitors $(57 \%)$ and served a higher percentage $(37 \%)$ of the state population. People in areas served by the less utilized ERs traveled more miles to be cared for $(7.1$ miles vs 5.4 miles; $\mathrm{p}<0.0001)$. Logistic regression analysis revealed that shorter distances were associated with increased use of the ERs, even after controlling for socio-demographic factors. The conclusion is that Mississippi ERs are typically located in block groups with higher percentages of disadvantaged residents and that people in these areas are more likely to utilize ER services. Our data suggest that the geographical distance has an impact on ER utilization, especially by reducing utilization in disadvantaged block group areas. Disadvantaged persons living near ER hospitals ( $<5$ miles) were found to be more likely to utilize the ER services. Geographic distance should therefore be considered when planning state-wide ER programmes for disadvantaged populations.
\end{abstract}

Keywords: geographic distance, emergency room, utilization, geographical information systems, community-level analysis.

\section{Introduction}

The primary function of a hospital-based emergency room (ER) is to treat patients suffering from

Corresponding author:

William B. Ward

USF Health

13201 Bruce B. Downs Blvd MDC 56

Tampa, Florida 33612, USA

Tel. +1 813205 6269; Fax +1 8132547813

E-mail: wward@hsc.usf.edu an acute, serious illness or injury that would lead to an increasingly severe condition if not tended to.

National trends show both increased use of hospital-based ERs and a decreasing availability of resources. While the number of ER visits has increased $18 \%$ over the last 10 years, i.e. from 93.4 million in 1994 to 110.2 million in 2004 (Burt and McCaig, 2001), the number of hospital ERs in the United States of America (USA) has decreased by about $12.4 \%$ during the same period (McCaig and Nawar, 2006). The report shows that a considerable 
proportion of visits to ERs in hospitals in the USA were non-emergent cases. Of the 110.2 million annual visits to the ERs, nearly 54 million cases $(49 \%)$ were for treatment of non-acute patients. In addition to unnecessarily increasing medical costs, the growing trend of non-emergency ER visits may have an adverse impact on the ability to care for severely ill or injured patients. Last year, Mississippi had 528.1 ER visits per 1,000, the third highest rates in the USA (American Indicators-Health, 2006). We would expect that among these there exists a preponderance of non-urgent visits.

In the last century, the greatest increases of ER visits were among those with illnesses rather than injuries. Most of them were African Americans over 65 years of age. Meggs et al. (1999) found that ER use in a rural area increased $50 \%$ faster than population growth over a 10 -year period. The percentage of urgent cases increased as well, perhaps as a result of increases in waiting time and lack of access to a primary-care facility. Phelps et al. (2000) found that the greatest increases in ER visits occurred among single parents with children covered by Medicaid. Increased parental ER utilization is significantly associated with increased childhood ER utilization (Mistry et al., 2005). Increased age, increased acuity, being an African American, living in a rural area, and having limited access to primary-care physicians, all contribute to increased ER demand (Meggs et al., 1999; Phelps et al., 2000; Burt and McCaig, 2001; Reeder et al., 2002).

In spite of many studies identifying factors influencing ER utilization, there are only a limited number of assessments of how the geographic distance affects ER utilization (Ingram et al., 1978; Magnusson, 1980). Moreover, these studies do not consider, in any detail, community characteristics when assessing the relationship between distance and utilization. Our study attempts to build a state-wide model to determine the impact of distance on utilization. The aim is to estimate the distances that potential patients in Mississippi must travel to access ER under hypothetical situations, as well as to determine whether an association exists between geographic distance and ER utilization.

\section{Materials and methods}

\section{Geographic distances and sources of data}

We identified 89 hospitals providing ER services in Mississippi. The hospitals were geocoded by using ArcView version 3.0, a commercial geographical information system (GIS) software programme produced by Environmental Systems Research Institute, Inc. (ESRI; Redlands, CA, USA). Geocoding is a process in which data elements are imported and assigned geographic coordinates (latitude and longitude). Population-weighted block group centroid locations were obtained from Spatial Insights, Inc. (Falls Church, VA, USA). Geographic distances between each hospital and each population-weighted block group centroid were calculated. Because of the near-spherical shape of the Earth (technically an oblique spheroid), we used spherical geometry and trigonometric mathematical functions in calculating an accurate distance between two points, i.e. the great circle distance formulas.

We obtained 2000 census data for block groups from the US Census Bureau. The population data for each block group were assigned to their respective centroids. Census variables included those related to known risk factors (i.e. age, gender and ethnic background) found to affect ER utilization and potential modifiers of ease of access to medical facilities (education, income, etc.). The literature shows a clear link between socio-economic status and health (Minkler et al., 2006). Among 2,148 block groups in Mississippi investigated, the majority of those with higher than average ER utilization were found to be above the state average in people aged above 65 years $(51 \%)$, in females $(53 \%)$, in those owning their residences (59\%), in those having lived in the same house for the last five years $(58 \%)$, and in the white population (54\%). Meanwhile, a lower proportion of block groups was found to be above 
the state average with regard to the median household income $(42 \%)$ and to the median house value $(34 \%)$. The same held for persons with a bachelor's degree or higher $(32 \%)$, those living below the poverty line $(44 \%)$, the unemployed $(41 \%)$, households headed by a female $(43 \%)$, those aged 10 years or younger (48\%) and African Americans (46\%).

Map and brief statistics on Mississippi are shown in Figure 1.

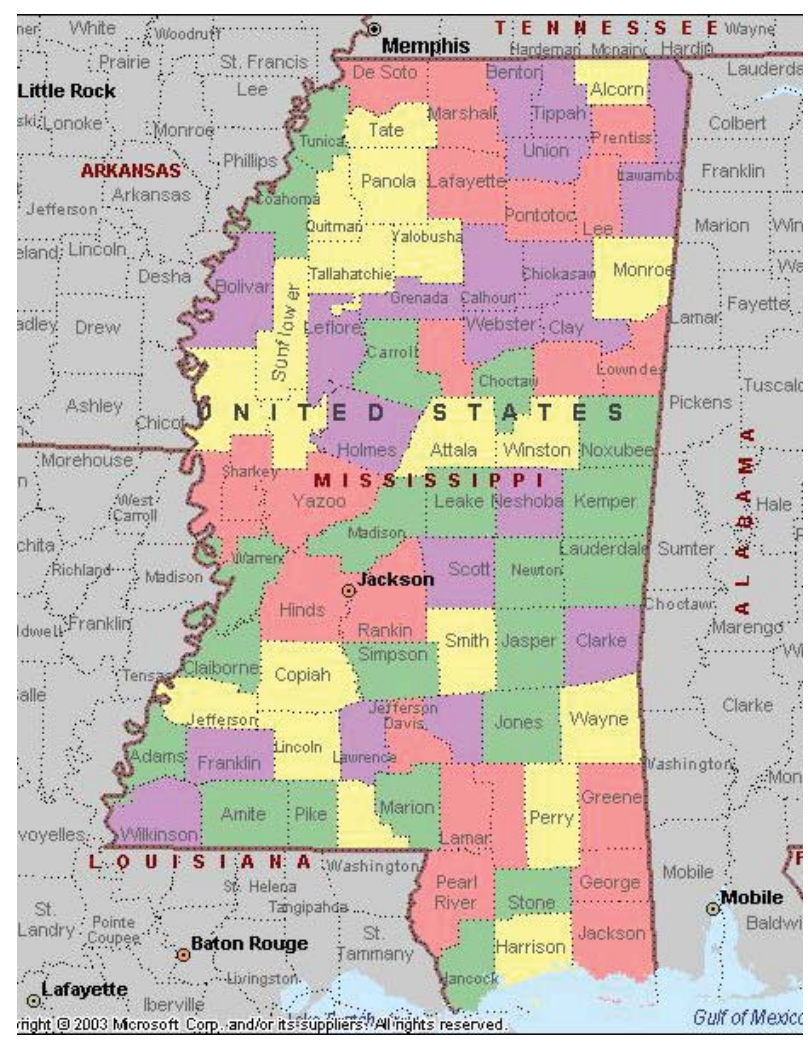

Fig. 1. Mississippi, a southern State of the USA, is situated with the State of Tennessee to the north, the State of Alabama to the east, the State of Louisiana and the Gulf of Mexico to the south, and the states of Louisiana and Arkansas to the west across the Mississippi River. With regard to population (2,844,658 people in 2000), it ranks 31st and its proportion (37\%) of African American population is the highest in the USA. One third of Mississippians live in the Jackson metropolitan area. (http://www.answers.com/topic/mississippi). The State has the highest mortality rate for heart disease and motor vehicle accidents (http://www.statehealthfacts.org/cgi-bin/healthfacts.cgi? action $=$ compare $\&$ category $=$ Health + Status \&subcategory $=$ Heart + Disease\&topic $=$ Heart+Disease+Death + Rate + per $+100 \% 2$ C000).

\section{Service area and area hospital}

A service area (SA) is a set of block groups expected to be served by an area hospital due to geographic proximity with the provision that a rational patient (or an emergency dispatcher) would use the ER closest to their residence. This is based on the assumption that, if given enough information regarding the distance, people would compare the distances and choose (or a health care manager assign patients to) the hospital closest to where they live. The SA sizes were measured by the number of block groups, the land size, or the number of people depending on each hospital in the model and the location of these hospitals. By definition, only a single hospital can exist in a single SA and a block group belongs to only one SA and is served by one area hospital. On average, the SAs had $24 \pm 14$ block groups, $527 \pm 255$ square miles of land, and a population size of $31,962 \pm 21,739$. Area hospitals in metropolitan areas serve a greater number of block groups, and consequently a larger population, but a smaller area.

\section{Utilization rate}

The Mississippi State Department of Health regularly produces an annual survey of hospitals which contains the latest information regarding location, ownership, service utilization, and management of its hospitals. Using the 2003 Mississippi ER visitors database, we calculated the utilization ratios (URs) by estimating the ratios of the expected number of visits to an area hospital to the observed number of visits for a 12-month period. Since we assumed that the incidence of a specific emergent condition is proportional to population size, the URs can be calculated by dividing the proportion of patients visiting the area hospital by the proportion of population within the SA in question. For example, if a SA consists of $10 \%$ of the total State population and the hospital in the SA treats $7 \%$ of total state ER visitors, $70 \%$ of the potential patients in the SA utilize the area hospital and $30 \%$ may choose, or be 
Table 1. Block groups and populations by distance to ER facility.

\begin{tabular}{|c|c|c|c|c|c|c|}
\hline \multirow{2}{*}{$\begin{array}{l}\text { Distance } \\
\text { (miles) }\end{array}$} & \multicolumn{3}{|c|}{ Block groups } & \multicolumn{3}{|c|}{ Population } \\
\hline & Number & $\%$ total & Cumulative & Number & $\%$ total & Cumulative \\
\hline$<1$ & 250 & 11.6 & 11.6 & 275024 & 9.7 & 9.7 \\
\hline $1-2$ & 295 & 13.7 & 25.4 & 357033 & 12.6 & 22.2 \\
\hline $2-3$ & 235 & 10.9 & 36.3 & 313755 & 11.0 & 33.2 \\
\hline $3-4$ & 168 & 7.8 & 44.1 & 238611 & 8.4 & 41.6 \\
\hline $4-5$ & 135 & 6.3 & 50.4 & 194358 & 6.8 & 48.5 \\
\hline $5-6$ & 125 & 5.8 & 56.2 & 183208 & 6.4 & 54.9 \\
\hline $6-7$ & 113 & 5.3 & 61.5 & 149300 & 5.2 & 60.2 \\
\hline $7-8$ & 108 & 5.0 & 66.5 & 157076 & 5.5 & 65.7 \\
\hline $8-9$ & 103 & 4.8 & 71.3 & 146251 & 5.1 & 70.8 \\
\hline $9-10$ & 107 & 5.0 & 76.3 & 147976 & 5.2 & 76.0 \\
\hline $10-11$ & 88 & 4.1 & 80.4 & 118401 & 4.2 & 80.2 \\
\hline $11-12$ & 91 & 4.2 & 84.6 & 120268 & 4.2 & 84.4 \\
\hline $12-13$ & 68 & 3.2 & 87.8 & 98904 & 3.5 & 87.9 \\
\hline$\geq 13$ & 262 & 12.2 & 100.0 & 344493 & 12.1 & 100.0 \\
\hline
\end{tabular}

transferred to, another hospital. However, although we must assume that the emergency operators (e.g. 911 or ambulance personnel) have correct information and that they would direct patients to the hospitals closest to the callers homes, there is a low possibility of patients being directed to other than the area hospital. Because emergency patients require urgent care, we may assume the emergency operator would refer patients to the nearest ER. For the purpose of analysis, a utilization rate less than $100 \%$ of that expected is referred to as a "lowly-used" area and a rate $100 \%$ or more is referred to as a "highly-used" area. Among 89 total hospitals with ERs, 60 hospitals $(67 \%)$ were classified as lowly-used and $29(33 \%)$ as highly-used.

\section{Analysis}

Logistic regression was conducted to test if distances between the residence and the nearest ER hospital differed among the subgroups of sociodemographic variables. Independent variables were dichotomized into low and high by the value of the State average of the variable. Prevalence, expressed in percents, odds ratios (ORs) and 95\% confidence intervals (CIs), was reported as well as the Wald-test p-values. We also conducted logistic regression analysis to determine if the level of uti- lization differed by the distance between the patients' residence and the ERs. We reported odds ratios after controlling for major demographic variables. We then produced a multivariate logistic regression model by including factors found significant in univariate analyses to determine which variables would best predict highly-used. All analyses were performed using SAS (Base SAS ${ }^{\circledR}$ 9.1.3, 2006, SAS Institute Inc., Cary, NC, USA).

\section{Results}

Table 1 represents the number of block groups and population by the number of miles that patients minimally would have to travel to get to the nearest ER.

Almost one in two Mississippians were found to live within 5 miles of an ER hospital, but the majority $(51.5 \%)$ needed to travel 5 or more miles from their residences. About 1 in 4 people $(24.0 \%)$ lived 10 or more miles away from the nearest hospital.

The disparity in geographic access to the nearest ER hospital was clear among the subgroups of sociodemographic variables. Communities with a higher proportion of educated, elderly people living in higher than median-valued houses, female householders, females in general, African Americans and people below the poverty level were more likely to be locat- 
Table 2. Distance to ER hospitals by socio-demographic variables: results of logistic regression analysis.

\begin{tabular}{|c|c|c|c|c|c|c|c|c|}
\hline & \multicolumn{2}{|c|}{ Block groups } & \multirow{3}{*}{$\begin{array}{c}<5 \text { miles } \\
(\mathrm{n}=1084) \\
\\
\%\end{array}$} & \multirow{3}{*}{$\begin{array}{c}>5 \text { miles } \\
(\mathrm{n}=1064)\end{array}$} & \multirow[b]{3}{*}{ OR } & & & \multirow[b]{3}{*}{ p-value } \\
\hline & \multirow[b]{2}{*}{$\mathrm{N}$} & \multirow[b]{2}{*}{$\%$} & & & & \multicolumn{2}{|c|}{$95 \% \mathrm{CI}$} & \\
\hline & & & & & & $\begin{array}{c}\text { Lower } \\
\text { limit }\end{array}$ & $\begin{array}{c}\text { Upper } \\
\text { limit }\end{array}$ & \\
\hline & 2148 & & 50.4 & 49.6 & & & & \\
\hline Median household income & & & & & & & & \\
\hline Below State average $(<$ US\$ 31,300) & 1251 & 58.2 & 58.9 & 57.6 & 1.05 & 0.89 & 1.25 & 0.559 \\
\hline Above the State average ( $\geq$ US\$ 31,300 ) & 897 & 41.8 & 41.1 & 42.4 & & & & \\
\hline Median house value & & & & & & & & \\
\hline Below State average $(<$ US\$ 71,400) & 1428 & 66.5 & 63.3 & 69.7 & 0.75 & 0.63 & 0.90 & 0.002 \\
\hline Above the State average (US\$ 71,400 ) & 720 & 33.5 & 36.7 & 30.3 & & & & \\
\hline Percentage of $65+$ years old & & & & & & & & \\
\hline Below State average $(<12.1 \%)$ & 1051 & 48.9 & 45.9 & 52.1 & 0.78 & 0.66 & 0.92 & 0.004 \\
\hline Above the State average $(\geq 12.1 \%)$ & 1097 & 51.1 & 54.2 & 47.9 & & & & \\
\hline Percentage of female & & & & & & & & \\
\hline Below State average $(<51.7 \%)$ & 1010 & 47.0 & 37.6 & 56.6 & 0.46 & 0.39 & 0.55 & $<0.0001$ \\
\hline Above the State average ( $\geq 51.7 \%)$ & 1138 & 53.0 & 62.4 & 43.4 & & & & \\
\hline Percentage of bachelor degree or higher & & & & & & & & \\
\hline Below State average $(<16.9 \%)$ & 1458 & 67.9 & 56.8 & 79.1 & 0.35 & 0.29 & 0.42 & $<0.0001$ \\
\hline Above the State average ( $\geq 16.9 \%)$ & 690 & 32.1 & 43.2 & 20.9 & & & & \\
\hline Percentage of owner occupied & & & & & & & & \\
\hline Below State average $(<72.3 \%)$ & 883 & 41.1 & 60.5 & 21.3 & 5.65 & 4.67 & 6.84 & $<0.0001$ \\
\hline Above the State average $(\geq 72.3 \%)$ & 1265 & 58.9 & 39.5 & 78.7 & & & & \\
\hline Percentage of below poverty & & & & & & & & \\
\hline Below State average $(<19.9 \%)$ & 1202 & 56.0 & 52.4 & 59.6 & 0.75 & 0.63 & 0.89 & 0.001 \\
\hline Above the State average $(\geq 19.9 \%)$ & 946 & 44.0 & 47.6 & 40.4 & & & & \\
\hline Percentage living in same house for 5 years & & & & & & & & \\
\hline Below State average $(<58.8 \%)$ & 901 & 41.9 & 55.4 & 28.3 & 3.14 & 2.63 & 3.76 & $<0.0001$ \\
\hline Above the State average $(\geq 58.8 \%)$ & 1247 & 58.1 & 44.7 & 71.7 & & & & \\
\hline Percentage of white & & & & & & & & \\
\hline Below State average $(<61.4 \%)$ & 992 & 46.2 & 51.1 & 41.2 & 1.49 & 1.26 & 1.77 & $<0.0001$ \\
\hline Above the State average $(\geq 61.4 \%)$ & 1156 & 53.8 & 48.9 & 58.8 & & & & \\
\hline Percentage of unemployment & & & & & & & & \\
\hline Below State average $(<4.4 \%)$ & 1272 & 59.2 & 45.6 & 35.9 & 1.50 & 1.26 & 1.78 & $<0.0001$ \\
\hline Above the State average $(\geq 4.4 \%)$ & 876 & 40.8 & 54.4 & 64.1 & & & & \\
\hline Percentage of female householder & & & & & & & & \\
\hline Below State average $(<21.7 \%)$ & 1229 & 57.2 & 43.2 & 71.5 & 0.30 & 0.25 & 0.36 & $<0.0001$ \\
\hline Above the State average $(\geq 21.7 \%)$ & 919 & 42.8 & 56.8 & 28.5 & & & & \\
\hline Percentage of aged 10 or younger & & & & & & & & \\
\hline Below State average $(<16.4 \%)$ & 1126 & 52.4 & 53.2 & 51.6 & 1.07 & 0.90 & 1.27 & 0.449 \\
\hline Above the State average ( $\geq 16.4 \%)$ & 1022 & 47.6 & 46.8 & 48.4 & & & & \\
\hline Percentage of African American & & & & & & & & \\
\hline Below State average $(<36.3 \%)$ & 1168 & 54.4 & 49.9 & 58.9 & 0.69 & 0.59 & 0.82 & $<0.0001$ \\
\hline Above the State average $(\geq 36.3 \%)$ & 980 & 45.6 & 50.1 & 41.1 & & & & \\
\hline
\end{tabular}

$\mathrm{OR}=$ odds ratio; $\mathrm{CI}=$ confidence interval $\mathrm{n}=$ valid number of block groups in the analyses +Wald-test p-value 
Table 3. Land size, number of visitors, population and the average number of miles to travel to ER hospitals by level of usage rate.

\begin{tabular}{|c|c|c|c|c|c|c|c|c|c|}
\hline \multirow{2}{*}{ Usage rate } & \multicolumn{2}{|c|}{ Hospital } & \multicolumn{2}{|c|}{ Land size } & \multicolumn{2}{|c|}{ Visitor } & \multicolumn{2}{|c|}{ Population } & \multirow{2}{*}{$\begin{array}{c}\text { Average } \\
\text { distance to ER } \\
\text { (miles) }\end{array}$} \\
\hline & $\mathrm{N}$ & $\%$ total & $\mathrm{N}$ & $\%$ total & $\mathrm{N}$ & $\%$ total & $\mathrm{N}$ & $\%$ total & \\
\hline$<0.5$ & 17 & 19.1 & 9458.3 & 20.2 & 148115 & 9.2 & 564974 & 19.9 & 7.6 \\
\hline $0.5-0.8$ & 21 & 23.6 & 13971.9 & 29.8 & 200508 & 12.4 & 565208 & 19.9 & 7.7 \\
\hline $0.8-1.0$ & 22 & 24.7 & 10529.4 & 22.4 & 347869 & 21.6 & 672103 & 23.6 & 6.2 \\
\hline $1.0-1.2$ & 12 & 13.5 & 6037.9 & 12.9 & 230616 & 14.3 & 333448 & 11.7 & 6.2 \\
\hline $1.2-1.5$ & 7 & 7.9 & 3279.2 & 7.0 & 215858 & 13.4 & 312779 & 11.0 & 5.4 \\
\hline$\geq 1.5$ & 10 & 11.2 & 3630.2 & 7.7 & 469796 & 29.1 & 396146 & 13.9 & 4.9 \\
\hline Total & 89 & 100.0 & 46907.0 & 100.0 & 1612762 & 100.0 & 2844658 & 100.0 & \\
\hline
\end{tabular}

ed within 5 miles from the nearest ER hospital. On the other hand, areas situated 5 or more miles away from the nearest ER were generally made up of communities with a higher percentage of homeowners, people having lived in the same house for the last 5 years, white people in general, and people without employment. The median household income and the percentage of children aged 10 years or younger, however, were not associated with the distances from their residences to the nearest ER (Table 2).

Table 3 presents the number of hospitals, areas in square miles, the number of visits, population, and the average distance in miles from the area hospital nearest to the patients' residences by level of usage rate.

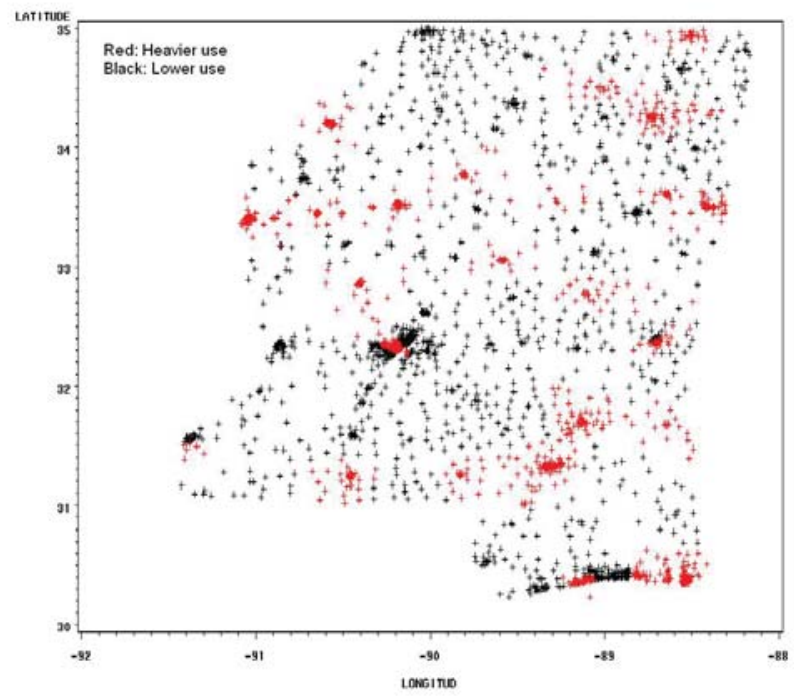

Fig. 2. Plots of block group centroids by level of ER utilization. Red indicated heavier use and black indicated lower use.
Twenty nine of the 89 hospitals $(33 \%)$ in the State of Mississippi were classified as having a high-utilization of ER services (usage rate 1 or greater). These hospitals serve a smaller area ( $28 \%$ of the total) but had a greater proportion of ER visitors $(57 \%)$ and population (37\% of the State population). People in the SAs served by the more highly utilized ERs traveled less miles from their residences $(7.1$ miles vs. 5.4 miles; $\mathrm{p}<0.0001)$. Figure 2 shows the block group centroids belonging to highly-used and lowly-used ER hospitals. The map indicates that the majority of the block groups belonging to the highly utilized ER hospitals are located in the downtown areas of big cities.

The level of ER utilization was found to vary among subgroups of residents in relation to their different socio-demographic characteristics, i.e. disadvantaged communities were significantly associated with highly-used ER hospitals, while more affluent ones were associated with lower utilized ERs. The latter communities were more likely to be represented by people with above median household incomes, above median house values, and better residential stability (homeowners or people with residential tenure). They also had a higher prevalence of white population, unemployed, and people located far from ER hospitals. Meanwhile, the highly-used ER hospitals were associated with communities with higher proportions of African Americans, people living below the poverty line, female householders, females in general, and children. The aged and the educated were not associated with the usage rate (Table 4).

This pattern of relationships persisted only within 
Table 4. Community-level socio-demographic factors associated with ER utilization: results of logistic regression analysis.

\begin{tabular}{|c|c|c|c|c|c|c|}
\hline & \multirow{2}{*}{$\begin{array}{c}\text { Lower use } \\
(\mathrm{n}=1304) \\
\%\end{array}$} & \multirow{2}{*}{$\begin{array}{c}\text { Heavier use } \\
(\mathrm{n}=844) \\
\%\end{array}$} & \multicolumn{4}{|c|}{$95 \% \mathrm{CI}$} \\
\hline & & & OR & $\begin{array}{c}\text { Lower } \\
\text { limit }\end{array}$ & $\begin{array}{l}\text { Upper } \\
\text { limit }\end{array}$ & p-value $\dagger$ \\
\hline Median household income & 60.7 & 39.3 & & & & \\
\hline $\begin{array}{l}\text { Below State average }(<\text { US\$ } 31,300) \\
\text { Above the State average }(\geq \text { US\$ } 31,300\end{array}$ & $\begin{array}{l}56.0 \\
44.0\end{array}$ & $\begin{array}{l}61.7 \\
38.3\end{array}$ & 0.79 & 0.66 & 0.94 & 0.008 \\
\hline $\begin{array}{l}\text { Median house value } \\
\text { Below State average }(<\text { US\$ } 71,400) \\
\text { Above the State average }(\text { US } \$ 71,400)\end{array}$ & $\begin{array}{l}64.1 \\
35.9\end{array}$ & $\begin{array}{l}70.1 \\
29.9\end{array}$ & 0.76 & 0.63 & 0.92 & 0.004 \\
\hline $\begin{array}{l}\text { Percentage of } 65+\text { years old } \\
\text { Below State average }(<12.1 \%) \\
\text { Above the State average }(\geq 12.1 \%)\end{array}$ & $\begin{array}{l}48.5 \\
51.5\end{array}$ & $\begin{array}{l}49.6 \\
50.4\end{array}$ & 0.95 & 0.80 & 1.13 & 0.594 \\
\hline $\begin{array}{l}\text { Percentage of female } \\
\text { Below State average }(<51.7 \%) \\
\text { Above the State average }(\geq 51.7 \%)\end{array}$ & $\begin{array}{l}49.2 \\
50.8\end{array}$ & $\begin{array}{l}43.6 \\
56.4\end{array}$ & 1.25 & 1.05 & 1.49 & 0.011 \\
\hline $\begin{array}{l}\text { Percentage of bachelor degree or higher } \\
\text { Below State average }(<16.9 \%) \\
\text { Above the State average }(\geq 16.9 \%)\end{array}$ & $\begin{array}{l}67.2 \\
32.8\end{array}$ & $\begin{array}{l}69.0 \\
31.0\end{array}$ & 0.92 & 0.77 & 1.11 & 0.388 \\
\hline $\begin{array}{l}\text { Percentage of owner occupied } \\
\text { Below State average }(<72.3 \%) \\
\text { Above the State average }(\geq 72.3 \%)\end{array}$ & $\begin{array}{l}34.6 \\
65.4\end{array}$ & $\begin{array}{l}51.2 \\
48.8\end{array}$ & 0.50 & 0.42 & 0.60 & $<0.0001$ \\
\hline $\begin{array}{l}\text { Percentage of below poverty } \\
\text { Below State average }(<19.9 \%) \\
\text { Above the State average }(\geq 19.9 \%)\end{array}$ & $\begin{array}{l}58.7 \\
41.3\end{array}$ & $\begin{array}{l}51.7 \\
48.3\end{array}$ & 1.33 & 1.12 & 1.59 & 0.001 \\
\hline $\begin{array}{l}\text { Percentage living same house for last } 5 \text { year } \\
\text { Below State average }(<58.8 \%) \\
\text { Above the State average }(\geq 58.8 \%)\end{array}$ & $\begin{array}{l}39.4 \\
60.6\end{array}$ & $\begin{array}{l}45.9 \\
54.2\end{array}$ & 0.77 & 0.65 & 0.92 & 0.003 \\
\hline $\begin{array}{l}\text { Percentage of white } \\
\text { Below State average }(<61.4 \%) \\
\text { Above the State average }(\geq 61.4 \%)\end{array}$ & $\begin{array}{l}43.0 \\
57.0\end{array}$ & $\begin{array}{l}51.1 \\
48.9\end{array}$ & 0.72 & 0.61 & 0.86 & $>0.001$ \\
\hline $\begin{array}{l}\text { Percentage of unemployment } \\
\text { Below State average }(<4.4 \%) \\
\text { Above the State average }(\geq 4.4 \%)\end{array}$ & $\begin{array}{l}38.5 \\
61.5\end{array}$ & $\begin{array}{l}44.3 \\
55.7\end{array}$ & 0.79 & 0.66 & 0.94 & 0.007 \\
\hline $\begin{array}{l}\text { Percentage of female householder } \\
\text { Below State average }(<21.7 \%) \\
\text { Above the State average }(\geq 21.7 \%)\end{array}$ & $\begin{array}{l}58.8 \\
41.2\end{array}$ & $\begin{array}{l}54.7 \\
45.3\end{array}$ & 1.18 & 0.99 & 1.41 & 0.062 \\
\hline $\begin{array}{l}\text { Percentage of aged } 10 \text { or younger } \\
\text { Below State average }(<16.4 \%) \\
\text { Above the State average }(\geq 16.4 \%)\end{array}$ & $\begin{array}{l}54.3 \\
45.7\end{array}$ & $\begin{array}{l}49.5 \\
50.5\end{array}$ & 1.21 & 1.02 & 1.44 & 0.031 \\
\hline $\begin{array}{l}\text { Percentage of African Americans } \\
\text { Below State average }(<36.3 \%) \\
\text { Above the State average }(\geq 36.3 \%)\end{array}$ & $\begin{array}{l}57.3 \\
42.7\end{array}$ & $\begin{array}{l}49.9 \\
50.1\end{array}$ & 1.35 & 1.13 & 1.60 & $>0.001$ \\
\hline $\begin{array}{l}\text { Mileage from hospital } \\
\text { Within } 5 \text { miles } \\
5 \text { or more miles }\end{array}$ & $\begin{array}{l}44.7 \\
55.3\end{array}$ & $\begin{array}{l}59.4 \\
40.6\end{array}$ & 0.55 & 0.47 & 0.66 & $<0.0001$ \\
\hline
\end{tabular}

OR = odds ratio; $\mathrm{CI}=$ confidence interval $\mathrm{n}=$ valid number of block groups in the analyses †Wald-test p-value 
Table 5. Multivariate logistic regression analysis to predict over-use.

\begin{tabular}{|c|c|c|c|c|}
\hline & \multicolumn{4}{|c|}{ Multiple logistic regression } \\
\hline & \multirow[b]{2}{*}{ OR } & \multicolumn{2}{|c|}{$95 \% \mathrm{CI}$} & \multirow[b]{2}{*}{ p-value $\dagger$} \\
\hline & & Lower limit & Upper limit & \\
\hline Mileage from ER & 0.66 & 0.54 & 0.81 & $<0.0001$ \\
\hline Median household income & 1.08 & 0.84 & 1.39 & 0.543 \\
\hline Median house value & 0.76 & 0.60 & 0.96 & 0.026 \\
\hline Percentage of age of female & 1.01 & 0.84 & 1.22 & 0.920 \\
\hline Percentage of owner occupied & 0.62 & 0.49 & 0.78 & $<0.0001$ \\
\hline Percentage of poverty & 0.95 & 0.74 & 1.23 & 0.712 \\
\hline Percentage living in same house for 5 years & 0.96 & 0.78 & 1.18 & 0.683 \\
\hline Percentage of white & 0.86 & 0.49 & 1.52 & 0.600 \\
\hline Percentage of unemployment & 1.02 & 0.82 & 1.25 & 0.887 \\
\hline Percentage of aged younger than 10 & 1.12 & 0.93 & 1.36 & 0.233 \\
\hline Percentage of African Americans & 0.91 & 0.52 & 1.61 & 0.755 \\
\hline
\end{tabular}

$\mathrm{OR}=$ odds ratio $; \mathrm{CI}=$ confidence interval

†Wald-test p-value

a 5-mile area of the ER hospitals. The block group characteristics of the disadvantaged, such as poverty $(\mathrm{p}<0.0001)$ and a high proportion of African Americans $(p<0.0001)$, were associated with more highly utilized ER hospitals. More affluent people, such as those with median incomes $(p<0.0001)$, median house values $(\mathrm{p}<0.0001)$, educated people $(\mathrm{p}=0.0019)$, homeowners $(\mathrm{p}<0.0001)$ and white populations $(\mathrm{p}<0.0001)$, were associated with less utilized hospitals. Of those living 5 or more miles away from an ER hospital only African Americans $(\mathrm{p}=0.086)$ and homeowners $(\mathrm{p}=0.012)$ were associated with lower ER utilization. It was found that people living in areas with less utilized ER services would have to travel greater distances even after controlling for major demographic variables (Table 5).

In addition, multivariate analysis revealed that overrepresentation of median-value houses and homeowners were associated with lower utilization of ER.

\section{Discussion}

Distances which Mississippians must travel to get to one of the 89 hospitals with ERs in the State have been estimated and tested for associations between ER utilization and distance traveled. Our data revealed that the average journey to gain access to an ER hospital amounts to 6.1 miles, and that a quarter of all people in Mississippi lives 10 or more miles away from the closest such facility. While the educated, the elderly, those living in houses above the median-value, females in general, and people below the poverty line, were found to be more likely to live in communities located within 5 miles of the nearest ER hospital, communities located further away had a higher percentage of homeowners, people having lived in same house for the last 5 years, and whites in general but there was also a higher proportion of unemployed in this group. The disparity in geographic access to ER facilities, however, may be related to the degree of urbanity rather than to disparity in socio-economic status. Our study shows that the community characteristics representing rural or suburban areas such as a high residential stability (homeowners or people having lived in the same house for the last 5 years) and a high proportion of white people were associated with longer travel to gain access to ER services. Conversely, the general characteristics of urban areas, such as a high proportion of educated people, but also high poverty and a relatively high number of African Americans, were found to be associated with fewer miles to the closest ER service. This sug- 
gests that disadvantaged populations are more likely to live in an urban area resulting in easier access to ER services. As McCaig and Nawar (2006) have pointed out, approximately two-thirds $(65.9 \%)$ of all hospital ERs in the USA are located in metropolitan statistical areas (MSAs) whose ERs are responsible for $86.0 \%$ of all annual ER encounters. Similar patterns may exist in Mississippi. Given that the rural roads are usually no wider than two lanes, the time spent on the road is generally greater than it would appear from the map alone. Due to the prevailing low population density, the likelihood of relocating large facilities to such areas is virtually zero. Access to ER facilities for those living in rural areas may therefore be worse than thought and populations living under such circumstances should be targeted for policy changes aimed at improving, for example, ambulance coverage, primary care facilities to address non-urgent health issues, and telemedicine.

One positive sign may be that populations most at risk are also the most likely to be in a position to reach hospital ERs speedily. Our data show that the people in communities with a high proportion of elderly individuals (65 years of age or older) are generally relatively close to ER services. This age group was also found to have the highest numbers of emergent or urgent visits to the ER (McCaig and Nawar, 2006). They may self-select to be closer to hospital facilities or they may have been defined as high-risk people when they first gained access to care and that this made them move closer.

Our data suggest that those living in disadvantaged block groups are more likely to utilize the emergency rooms. That is, when distances are equal, block groups with a high proportion of poverty and/or a high number of African Americans were found to be associated with more highly utilized ERs, while those with above median incomes and house values, higher proportions of educated and white people, and those having a stable residential status, were found to be associated with less utilized ER services. Our data, however, do not show if the higher utilization, which occurred in the disadvan- taged block groups, was linked to unwarranted use. We assumed that the occurrence of emergent events is proportional to population size. This assumption may, however, not be true because true emergency events may be more likely in the disadvantaged block groups due to their more accident-prone environment. Moreover, disadvantaged groups (which may have a disproportionate participation of African Americans due to their generally lower average incomes) have higher mortality rates and carry a higher risk of chronic diseases and may thus be more likely to enter into an ER situation. A higher utilization by deprived ER neighbourhoods may therefore not always mean that the utilization is unwarranted. However, as evidenced in a study by Jones et al. (1982) reporting that ER in deprived areas serve as the poor person's doctor, the data imply that part of higher utilization in deprived neighbourhoods may be associated with 'non-urgent visits'. Further study is required to elucidate this question.

The results reported here are consistent with another study indicating that children visit ER more often than other groups (McCaig and Nawar, 2006) and that communities with a high proportion of children are significantly associated with a higher utilization of ER services. It was also found that communities with a higher proportion of females (who are commonly single mothers) as heads of the household were marginally associated with higher ER utilization. Our data therefore found a likelihood of increased ER visits by children of single parents. However, since we did not have the identical variables as those reported by Phelps et al. (2000) it was not possible to determine completely if his findings are supported by our data.

The geographic distance may have a strong negative impact on ER utilization as suggested by our study. Less mileage from an ER hospital was found to be significantly associated with a higher utilization of ER services. A similar pattern was observed even in a multiple logistic regression model controlling for all socio-economic factors, which were significant in univariate analysis. Additionally, we have tried to determine the modifying effect of distance 
on the relationship between usage rate and socioeconomic status. The part of our analysis focusing on distance (within 5 miles vs. 5 or more miles) reveal that, within the 5-mile area, the community characteristics of the disadvantaged due to poverty and/or belonging to the African American community, were associated with highly utilized ER hospitals. On the other hand, people characterized as affluent due to median incomes, median house values, being educated, being homeowners and or belonging to the white population, were associated with lower utilization of ER hospitals. Interestingly, only African Americans and homeowners were associated with lower utilization among those living 5 or more miles away from an ER facility. This result, although the statistical significance $(\mathrm{p}=0.086)$ did not reach the $5 \%$ level, implies that distance has a positive impact on the usage rate for disadvantaged people living near ER hospitals, while disadvantaged populations living further away less often gain access to ER services.

The fact that multivariate analysis revealed that median house values and homeowners were associated with lower utilization of ER may be due to the fact that ERs are attached to hospitals and hospitals do not enhance surrounding land values. The location of ERs near the poor is a very usual pattern in the USA.

The findings presented here must be interpreted in the context of the specific limitations of the study. Firstly, the distances that we calculated were based on the great circle distance formula which assumes that the space is isotropic. Absolute (stop movements/interactions, mountain ranges, rivers/ oceans, etc.) and relative (frictions that vary according to direction and to features of space, slope, type of roads, border, etc.) barriers were not considered in our calculations. Secondly, for purposes of analysis, we assumed that Mississippians use only ER hospitals in Mississippi. Those living close to the State borders, however, may use ER hospitals in other States. We also assumed that ER hospitals in Mississippi serve only Mississippians. The discharge data, of course, may include those from other States.
However, the proportion of these people was not deemed to be high enough to have an impact on our calculations. Thirdly, we assumed that the specific emergency incidences generally occur in the vicinity to where people live (Robertson, 1998). Since most emergencies do occur within a couple of miles from a residence, this potential error is probably negligible.

Despite these limitations, our results indicate that Mississippi ER hospitals are surrounded by disadvantaged neighborhoods and that the people in these areas are more likely to utilize these ER services. In addition, disadvantaged people living in areas relatively far away from hospital services are less likely to use them. Since the data suggest that geographical distance has an impact on ER utilization, especially in disadvantaged communities, distance should be considered when developing statewide programmes for the disadvantaged populations who live far from ER hospitals.

\section{Summary of policy implications}

A statewide system could be developed on the basis of GIS interfaces to direct injured people to the closest, most appropriate facility based on the nature of the problem, the resources at the facility, travel time, insurance coverage, staff and bed availability, and the like.

The usefulness of a telephone triage system should be investigated with regard to its possibility to rapidly identify the most appropriate referral facility based on the seriousness and urgency of the situation, offering alternative routes to treatment, and tracking the outcome of the visit to determine efficiency and effectiveness of the services.

There is a need to update statewide population distribution and concentrations to assess where to open additional ERs or non-urgent care centers.

A system of consumer information should be put in place that would direct staff assisting injured people to the most appropriate location at any given time.

A spatial information decision making system should be developed at the State level as discussed 
by Chen et al. (1996) and, in times of great calamities (e.g. hurricanes, tornadoes, etc.), a system should be available for the distribution of potentially large number of injured people to ERs with unused capacity.

Excess ER capacity should be located to areas of the State where insurance coverage is low. As discussed by Ormond and Ullman (2002), the State of Mississippi has made a commitment to the rural areas and has used expanded Medicaid funding and money from the Tobacco litigation settlement to begin to do this.

\section{References}

American Indicators-Health, 2006. The progressive review, http://prorev.com/statshealth.htm.

Burt CW, McCaig LF, 2001. Trends in hospital emergency department utilization: United States, 1992-99. Vital Health Stat 13, 150, 1-34.

Chen MS, Park JS, Yu PS, 1996. Data mining for path traversal patterns in a web environment. Proceedings of the 16th International Conference on Distributed Computing Systems, 385-392.

Ingram DR, Clarke DR, Murdie RA, 1978. Distance and decision to visit an emergency department. Soc Sci Med 12, 55-62.
Jones PK, Jones SL, Yoder L, 1982. Hospital location as a determinant of emergency room utilization patterns. Public Health Rep 97, 445-451.

Magnusson G, 1980. The role of proximity in the use of hospital emergency departments. Sociol Health Illn 2, 202-214.

McCaig LF, Nawar EN, 2006. National hospital ambulatory medical care survey: 2004 emergency department summary. Advance data from vital and health statistics; no. 372. Hyattsville, MD: National Center for Health Statistics.

Meggs WJ, Czaplijski T, Benson N, 1999. Trends in emergency department utilization, 1988-1997. Acad Emerg Med 6, 1030-1035.

Minkler M, Fuller-Thomson E, Guralnik JM, 2006. Gradient of disability across the socioeconomic spectrum in the United States. New Engl J Med 355, 695-703.

Mistry RD, Hoffmann RG, Yauck JS, Brousseau DC, 2005. Association between parental and childhood emergency department utilization. Pediatrics 115, e147-151.

Ormond BA, Ullman F, 2002. Recent changes in health policy for low-income people in Mississippi. The Urban Institute, State update No. 20, February 2002.

Phelps K, Taylor C, Kimmel S, Nagel R, Klein W, Puczynski S, 2000. Factors associated with emergency department utilization for nonurgent pediatric problems. Arch Fam Med 9, 1086-1092.

Reeder T, Locascio E, Tucker J, Czaplijski T, Benson N, Meggs W, 2002. ED utilization: the effect of changing demographics from 1992 to 2000. Am J Emerg Med 20, 583-587.

Robertson LS, 1998. Injury epidemiology: research and control strategies. Robertson LS ed. New York, Oxford University Press. 